IDEAS AND

\title{
PERSPECTIVES Increased susceptibility to oxidative stress as a proximate cost of reproduction
}

\author{
Carlos Alonso-Alvarez * \\ Sophie Bertrand ${ }^{1}$, \\ Godefroy Devevey², \\ Josiane Prost ${ }^{3}$, Bruno Faivre ${ }^{2}$ \\ and Gabriele Sorci ${ }^{1}$ \\ ${ }^{1}$ Laboratoire de Parasitologie \\ Evolutive, CNRS UMR 7103, \\ Université Pierre et Marie Curie, \\ xquai St. Bernard, 75252 Paris \\ cedex 05, France \\ ${ }^{2}$ UMR CNRS 5561 BioGéo \\ Sciences, Equipe Ecologie \\ Evolutive, Université de \\ Bourgogne, 6 Blvd Gabriel, \\ 21000 Dijon, France \\ ${ }^{3}$ UPRES Lipides Nutrition, \\ Université de Bourgogne, EA \\ 2422, 6 Blvd Gabriel, 21000 \\ Dijon, France \\ *Correspondence: E-mail: \\ calonso@snv.jussieu.fr
}

\begin{abstract}
In iteroparous species high investment in current reproduction is usually paid in terms of reduced future reproduction and increased mortality. However, the proximal mechanisms of these costs remain poorly understood. Free radicals arising as by-products of normal metabolic activities have deleterious effects on cellular proteins, lipids and DNA, and this phenomenon is known as oxidative stress. Since reproduction is an energetically demanding activity, which increases both basal and field metabolic rates, one could expect that breeding effort generates an oxidative stress whose strength depends on the availability and efficiency of antioxidant defences. In agreement with this prediction, we show here for the first time that reproduction decreases antioxidant defences, illustrating that oxidative stress represents a cost of reproduction. We suggest that increased susceptibility to oxidative stress might be a general proximal connection between reproduction and survival underlying other mechanistic links previously acknowledged.
\end{abstract}

\section{Keywords}

Breeding effort, free radicals, sex-related breeding costs, zebra finch.

\section{INTRODUCTION}

A major assumption of models on the evolution of life histories is that increased allocation of energy/resources into one function cannot be achieved without diverting energy/resources from another function (Stearns 1992). In other terms, according to these models, life history traits are linked in a way that impedes the evolution of Darwinian demons (Law 1979).

A classic example of such trade-offs is the cost of reproduction, where elevated breeding effort leads to lowered subsequent fecundity or survival (Stearns 1992). The cost of reproduction has been broadly measured in terms of its ultimate consequences (negative impact on future survival or fecundity, Reznick 1992), however, the underlying proximate physiological mechanisms have only been investigated in the last years (Rose \& Bradley 1998; Zera \& Harshman 2001; Barnes \& Partridge 2003).

Although most models of life history evolution are based on the principle of energy/resource allocation (e.g. Reznick et al. 2000), the currency that is actually traded against conflicting functions is still under debate (Zera \& Harshman 2001; Barnes \& Partridge 2003). The most obvious link between reproduction and survival is energy (Rogowitz 1996; Niewiaroski 2001). Energy allocated to reproduction is no longer available for self-maintenance, and as the amount of energy allocated to reproduction increases, the magnitude of the survival cost also increases. However, this energy allocation model has been recently challenged in the light of results on the genetic control of development and ageing in organisms as diverse as nematodes (Caenorbabditis elegans) and laboratory mice (Gems et al. 1998; Clancy et al. 2001; Holzenberger et al. 2003). Similarly, the so-called 'income breeder' species (species that do not rely on energy reserves to start breeding) should be less sensitive to such energy-based trade-offs (Stearns 1992). Finally, although the cost of reproduction is paid in terms of energy, it is still unclear which vital functions of self-maintenance are involved in the trade-off.

Recently, much emphasis has been devoted to the role of immunosuppression and the related increase of parasitism risk as a proximate cost of reproduction. Costly sexual 
activities have been shown to compromise immunity in both invertebrates (McKean \& Nunney 2001) and vertebrates (Deerenberg et al. 1997). These results have been interpreted as evidence of the energy/resource trade-off between reproduction and survival, since reproduction diverts energy from the immune system. However, the energetic demands of the immune system have also been recently challenged (e.g. Råberg et al. 1998; Svensson et al. 1998), and although the activation of the immune system does induce an increase of the basal metabolic rate (Martin et al. 2002), it is still unclear whether this increase is enough to produce an energetic trade-off.

Here we suggest that increased susceptibility to oxidative stress might represent a general form of proximate cost of reproduction, independent of energy allocation. Oxidative stress is defined as an unbalance between the production of reactive oxygen species (ROS) and antioxidant compounds (Finkel \& Holbrook 2000). ROS are by-products of normal metabolic activities (Finkel \& Holbrook 2000). They are generally unstable and very reactive (Fang et al. 2002). Thus, they have a damaging effect on the principal bio-molecules such as DNA, proteins and lipids (Finkel \& Holbrook 2000). However, a number of endogenous and exogenous antioxidant defences exist, which scavenge ROS and limit their toxic effect (Surai 2002). The balance between ROS production and antioxidant defences determines the extent of the oxidative stress, the greater the production of ROS and the lower the antioxidant defences, the greater the oxidative stress. The role played by ROS in the ageing process has been recognized since long-time (Harman 1957). According to the free radical theory of ageing, the accumulation of ROS-induced damages through time would be the causal agent of the age-associated decline in performance (Finkel \& Holbrook 2000; Kirkwood \& Austad 2000). Surprisingly, however, the link between reproduction and oxidative stress has been only recently suggested (von Schantz et al. 1999; Salmon et al. 2001; Wang et al. 2001). It is well established that reproduction needs energy from the production of gametes to the raising of offspring (Zera \& Harshman 2001). Reproduction also increases activity in several species. As a consequence, reproduction increases energy expenditure through elevating both basal and field metabolic rate (Angilletta \& Sears 2000; Nilsson 2002). Since higher metabolism results in more ROS produced, one might expect that, unless the antioxidant defences also increase, reproduction should enhance the susceptibility to oxidative stress. To test this hypothesis, we manipulated breeding effort in captive zebra finches and investigated whether higher effort induces a reduction in the organismal resistance to a standardized free radical attack. In agreement with the prediction, we found that breeding effort was positively correlated with increased susceptibility to oxidative stress.

\section{MATERIALS AND METHODS}

\section{General procedures}

The study was conducted on captive zebra finches (Taeniopygia guttata) that had never bred before and that were all less than 1-year old. Forty-six randomly formed pairs were placed in breeding cages $(0.6 \times 0.4 \times 0.4 \mathrm{~m})$ with food (a commercial mix of seeds for exotic birds) and water ad libitum. A nest box and straw were provided for breeding, a blood sample was collected from the brachial vein, and the body mass measured $( \pm 0.1 \mathrm{~g})$. The breeding cages were maintained in a room with constant temperature $\left(21^{\circ} \pm\right.$ $1{ }^{\circ} \mathrm{C}$ ) and a light-dark daily cycle (13L : 11D). Thirty-six pairs bred and their brood size was manipulated as to create two groups: (i) pairs raising a two-chicks brood $(n=20)$; (ii) pairs raising a six-chicks brood $(n=16)$. Brood size was manipulated when nestlings were 2-days old in order to disrupt the natural covariation between brood size and parental quality. Initial clutch size did not differ between the groups that further received two or six chicks (two chicks: mean $\pm \mathrm{SE}=4.85 \pm 0.22$ eggs; six chicks: $4.88 \pm 0.46$ eggs; $\left.F_{1,34}=0.002, P=0.963\right)$. The 10 additional pairs did not breed during the course of the experiment. A second blood sample was collected for each individual when nestlings were 14-days old. For non-breeding individuals, the second blood sample was collected when the nestlings of the last breeding pair were 14-days old. Body mass $( \pm 0.1 \mathrm{~g})$ was again measured at the time of the second blood sampling. Two females (one in the non-breeding and one in the six-chick group) died during the course of the experiment and were therefore not re-sampled. As nonbreeding pairs might be a non-random sample of the total population, we checked whether there was a difference in body mass and antioxidant defences between the three groups (non-breeders, two-chicks, sixchicks). Neither body mass nor antioxidant defences differed among the three groups suggesting that initial conditions were similar for all birds (Table 1; body mass: breeding effort group: $F_{2,84}=1.25, \quad P=0.291$; sex, $F_{1,84}=0.35, \quad P=0.556$; sex $\times$ breeding effort group: $F_{2,84}=0.46, P=0.630 ;$ antioxidant defences: breeding effort group: $F_{2,84}=2.70, P=0.073$; sex, $F_{1,84}=9.43$, $P=0.003$; sex $\times$ breeding effort group: $F_{2,84}=0.81$, $P=0.447)$.

\section{Assessment of total antioxidant defences}

The total antioxidant defences in whole blood were assessed as the time needed to haemolyse $50 \%$ of the red blood cells exposed to a controlled free radical attack. We used the KRL test (Brevet Spiral V02023, Couternon, France; http://www.nutriteck.com/sunyatakrl.html) adapted to bird physiological parameters (osmolarity, temperature). The 
Table 1 Initial values of body mass and resistance to oxidative stress (time needed to haemolyse 50\% of the red blood cells exposed to a controlled free radical attack) for male and female zebra finches in the three breeding effort groups (non-breeding, two-chicks brood, sixchicks brood)

\begin{tabular}{|c|c|c|c|c|c|c|}
\hline & \multicolumn{2}{|c|}{ Non-breeders } & \multicolumn{2}{|c|}{ Two-chicks brood } & \multicolumn{2}{|c|}{ Six-chicks brood } \\
\hline & $\begin{array}{l}\text { Male } \\
(n=10)\end{array}$ & $\begin{array}{l}\text { Female } \\
(n=10)\end{array}$ & $\begin{array}{l}\text { Male } \\
(n=20)\end{array}$ & $\begin{array}{l}\text { Female } \\
(n=20)\end{array}$ & $\begin{array}{l}\text { Male } \\
(n=16)\end{array}$ & $\begin{array}{l}\text { Female } \\
(n=16)\end{array}$ \\
\hline Body mass (g) & $17.87(1.06)$ & $16.81(0.77)$ & $16.36(0.62)$ & $16.72(0.60)$ & $16.27(0.65)$ & $15.89(0.69)$ \\
\hline Resistance to oxidative stress (min) & $63.65(2.26)$ & $56.83(3.11)$ & $65.96(1.66)$ & $63.34(2.05)$ & $69.09(1.38)$ & $61.96(2.50)$ \\
\hline
\end{tabular}

Values are mean (SE).

principle of the test is to submit whole blood to a thermocontrolled free radical aggression [2,2'-azobis-(aminodinopropane) hydrochloride (AAPH)] (Rojas Wahl et al. 1998). All families of free radical scavengers present in the blood are mobilized to fight off the oxidant attack (Pieri et al. 1996; Girodon et al. 1997; Lesgards et al. 2002; Stocker et al. 2003). Twenty microlitres of blood were immediately diluted in $730 \mu \mathrm{L}$ of KRL buffer $\left(150 \mathrm{~mm} \mathrm{Na}^{+}, 120 \mathrm{~mm} \mathrm{Cl}^{-}, 6 \mathrm{mM}\right.$ $\mathrm{K}^{+}, 24 \mathrm{~mm}_{\mathrm{HCO}_{3}}^{-}, 2 \mathrm{~mm} \mathrm{Ca}{ }^{2+}, 340$ mosm, $\mathrm{pH}$ 7.4). Samples were stored at $4{ }^{\circ} \mathrm{C}$ before analysis, which occurred within $24 \mathrm{~h}$ following blood collection. Eigthy microlitres of KRL-diluted blood were incubated at $40{ }^{\circ} \mathrm{C}$ with $136 \mu \mathrm{L}$ of a $150 \mathrm{~mm}$ solution of AAPH. The lysis of red blood cells was assessed with a microplate reader device, which measures the decrease of optical density at the wavelength of $540 \mathrm{~nm}$.

\section{Statistical analyses}

Change in body mass (percentage-wise change of initial body mass) was assessed using a mixed model of variance with sex and breeding effort group as fixed factors and the cage identity as a random factor. Change in antioxidant defences (percentage-wise change of initial antioxidant defences) was assessed using a mixed model of covariance with sex and breeding effort group as fixed factors, change in body mass as a covariate and cage as a random factor. Statistical analyses were performed with SAS (proc MIXED, version SAS 8.2; SAS Institute 2001).

\section{RESULTS}

Increasing breeding effort induced a cost in terms of body mass loss for both males and females. Males showed an increase in body mass loss across the three breeding effort groups; whereas females lost a high proportion of initial body mass only when feeding a large brood (Fig. 1). This resulted in a statistically significant interaction between sex and breeding effort group (Table 2).

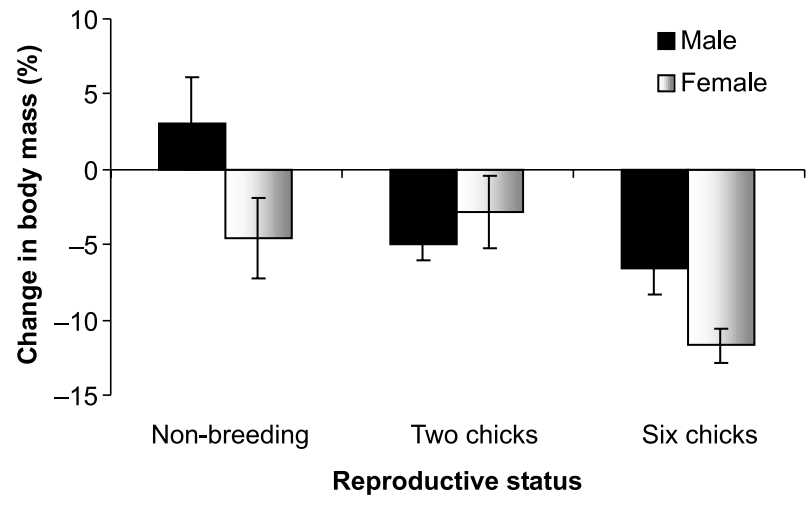

Figure 1 Percentage-wise change in body mass for male and female zebra finches experiencing different levels of breeding effort. Bars represent SE.

Table 2 Mixed model of variance on change in body mass (\%) with sex and breeding effort group as fixed factors and cage as a random factor

\begin{tabular}{llll}
\hline & d.f. & $F$-value & $P$-value \\
\hline Sex & 1,40 & 5.55 & 0.024 \\
Breeding effort group & 2,40 & 5.79 & 0.006 \\
Sex $\times$ breeding effort group & 2,40 & 4.87 & 0.013 \\
Random factor & & $Z$ & $P$-value \\
Cage & 2.34 & 0.010 \\
\hline
\end{tabular}

As for body mass, the effect of breeding effort on the change in resistance to oxidative stress was statistically different between sexes (Table 3). Scheffé's post-hoc comparisons showed that males raising a six-chicks brood suffered a significant reduction in antioxidant defences compared with non-breeding and two-chicks brood males ( $P=0.013$ and $P=0.010$, respectively; Fig. 2). Conversely, non-breeding females differed significantly from the other two groups $(P=0.003$ and $P=0.043$, respectively), whereas the difference between females in the two and six-chick brood groups was not statistically significant $(P=0.594$; Fig. 2). 
Table 3 Mixed model of covariance on change in resistance to oxidative stress (\%) with sex and breeding effort group as fixed factors, change in body mass $(\%)$ as a covariate, and cage as a random factor

\begin{tabular}{llll}
\hline & d.f. & $F$-value & $P$-value \\
\hline Sex & 1,39 & 4.02 & 0.052 \\
Breeding effort group & 2,39 & 7.01 & 0.003 \\
Sex $\times$ breeding effort group & 2,39 & 5.37 & 0.009 \\
Body mass change & 1,39 & 7.64 & 0.009 \\
Random factor & & $Z$ & $P$ \\
Cage & & 0.77 & 0.222 \\
\hline
\end{tabular}

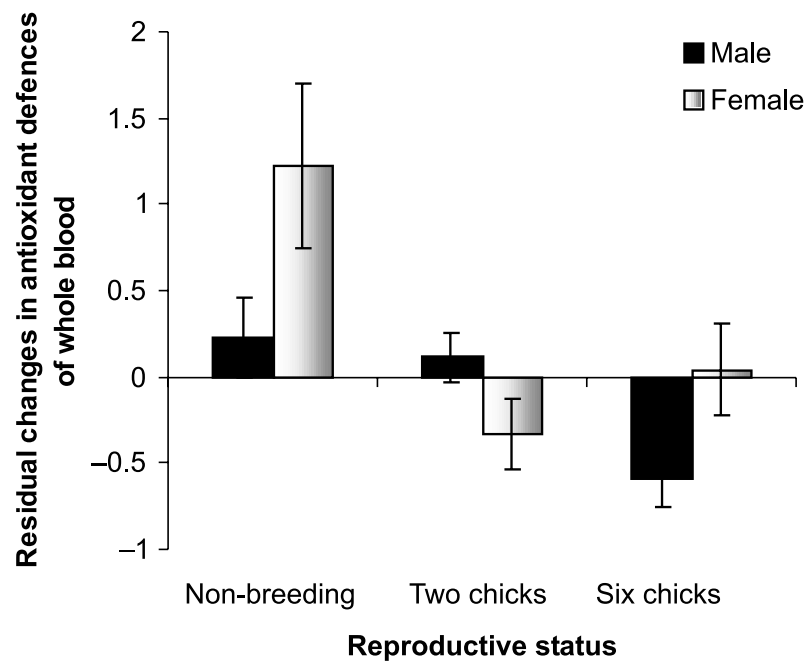

Figure 2 Body mass independent changes in antioxidant defences of whole blood for male and female zebra finches experiencing different levels of breeding effort. Bars represent SE.

\section{DISCUSSION}

To our knowledge, this is the first experimental evidence indicating that reproduction influences the total antioxidant defences in a vertebrate species. Given the role played by free radicals on the ageing process (Finkel \& Holbrook 2000), our results highlight a potential mechanism linking reproduction to longevity. The cumulative effect of oxidative stress across the reproductive life span might therefore explain the age-associated decline in performance commonly observed in iteroparous species (Kirkwood \& Austad 2000).

Interestingly, males and females differed in their response to the manipulation of breeding effort both in terms of body-mass change and change in resistance to oxidative stress. The change in resistance to oxidative stress of breeding females was much lower than non-breeding females, whereas resistance of breeding males was reduced only when they were forced to raise a large brood. Although differential sex-related body mass regulation during reproduction has been broadly reported in animals (Velando \& Alonso-Alvarez 2003), sex-related differences in the impact of breeding effort in terms of resistance to oxidative stress has never been reported. Such difference might reside in the sex-specific use of antioxidant defences, such as carotenoids, which are allocated to eggs by females (Royle et al. 2003) and immobilized in the keratin of the beak by males to produce a sexually selected trait (Blount $e$ al. 2003; Faivre et al. 2003). Whatever the physiological reason for this difference between sexes, our results suggest that males might be more vulnerable to an increase in breeding effort, in terms of decrease in antioxidant defences, than females. Obviously, further experimental work and replication of the present study using different organisms are needed to draw a firm conclusion.

The cost of reproduction is one of the central concepts of the evolution of life histories (Stearns 1992). Although energy-based models have been widely used to describe the currency of reproduction costs, the precise mechanistic bases of this trade-off have been rarely studied (Zera \& Harshman 2001; Barnes \& Partridge 2003). The most commonly evoked mechanistic link between reproduction and survival is energy. The nematode $C$. elegans has become one of the favourite model systems for the study of the genetic control of development, reproduction and ageing. Mutations in the genes of the insulin/IGF-like signalling pathway produce phenotypes that reallocate nutrients from reproduction to somatic maintenance, in agreement with the idea of a energy-based trade-off between reproduction and survival (Kenyon et al. 1993; Sze et al. 2000; Braeckman et al. 2001; Gems \& Partridge 2001). More recently, however, this view has been challenged by other results which suggest that the trade-off might be controlled by two distinct signalling mechanisms, independent of energy (Hsin \& Kenyon 1999; Leroi 2001; Arantes-Oliveira et al. 2002). Interestingly, similar results have been obtained with heterozygous knockout mice with inactivated IGF-1R (insulin-like growth factor type 1 receptor). These mice live longer than the wildtype whereas their fertility and reproduction are unaffected (Holzenberger et al. 2003). Although still debated (Barnes \& Partridge 2003; Lithgow \& Gill 2003), these results underline the necessity to integrate a better knowledge of the mechanistic bases of life history trade-offs into evolutionary models.

In this paper, we suggest that increased susceptibility to oxidative stress might be another mechanistic link between reproduction and survival, not directly dependent on energy-allocation. It is doubtless that reproduction requires energy (Zera \& Harshman 2001), and in order to fulfil such requirements, both basal and field metabolic rates are increased (Nilsson 2002). Higher metabolism inevitably 
corresponds to higher oxygen consumption and higher ROS production (Loft et al. 1994). ROS are very unstable compounds with potential damaging effect on cells and molecules such as DNA, proteins and lipids (Finkel \& Holbrook 2000). Surprisingly, despite the suspected role of ROS on ageing, the connection between ROS and the cost of reproduction has only recently been put forward.

Two recent studies carried out on Drosophila melanogaster showed that dietary (adding yeast to food) or hormonal manipulations (exposure to a juvenile hormone analogue) stimulated egg production and accelerated mortality (all flies died) after exposure to paraquat (a toxic compound used as an herbicide which generates oxygen radicals; Salmon et al. 2001; Wang et al. 2001). Although these studies did not directly manipulate reproductive effort and did not directly assess oxidative stress, the results are suggestive of a link between reproduction and increased susceptibility to ROS. We believe that our study goes further in showing the causal relationship between reproduction and oxidative stress for a number of reasons. We directly manipulated breeding effort in both males and females in a vertebrate species with biparental care, which allowed to assess sex-specific effects. Moreover, we used an assay of susceptibility to oxidative stress which provides an overall assessment of antioxidant defences mobilized to fight off a controlled free-radical attack, therefore avoiding any indirect toxic effect of the method.

Among the possible implications of our results, we suggest that increased oxidative stress due to reproductive effort could also contribute to explain breeding immunosuppression. Indeed, it has been shown that increased breeding effort compromises the functioning of the immune system and enhances the risk of parasitism (Deerenberg et al. 1997; Nordling et al. 1998). Courting, mating and feeding young are all activities which require physical effort and exercise. During exercise oxygen consumption can increase several times above the resting levels with a subsequent increase in the rate of mitochondrial free radical production (Alessio 1993). Free-radicals can damage DNA, including leucocyte DNA. Direct support to this hypothesis comes from studies on humans showing the effect of exercise (running a marathon) on the degree of unrepaired DNA base oxidation in leucocytes and a concomitant increase in the urinary excretion of 8-hydroxy-2'-deoxyguanosine (the most abundant product of oxidative DNA modifications) (Tsai et al. 2001). Therefore, free-radical production during activity can explain the reduced performance of the immune system, independently of the energetic demands associated with the maintenance of immune functioning. Obviously, we need more experimental work on this issue to establish the relative contribution of energetic trade-offs or free-radical mediated trade-offs on immunosuppression.
In conclusion, we suggest that increased susceptibility to oxidative stress might be a general form of cost of reproduction which might uncover other physiological link between reproduction and survival.

\section{ACKNOWLEDGEMENTS}

We are grateful to the staff of the Station Biologique de Foljuif for their help and Pascal Thouviot for technical assistance. Financial support was provided by the Ministère de la Recherche (ACI Jeunes Chercheurs to GS). CA-A was funded by Ministerio de Educación, Cultura y Deporte (Spain).

\section{REFERENCES}

Alessio, H.M. (1993). Exercise-induced oxidative stress. Med. Sci. Sports Exerc., 25, 218-224.

Angilletta, M.J. Jr \& Sears, M.W. (2000). The metabolic cost of reproduction in an oviparous lizard. Funct. Ecol., 14, 39-45.

Arantes-Oliveira, N., Apfeld, J., Dillin, A. \& Kenyon, C. (2002). Regulation of lifespan by germ-line cells in Caenorhabditis elegans. Science, 295, 502-505.

Barnes, A.I. \& Partridge, L. (2003). Costing reproduction. Anim. Behav., 66, 199-204.

Blount, J.D., Metcalfe, N.B., Birkhead, T.R. \& Surai, P.F. (2003). Carotenoid modulation of immune function and sexual attractiveness in zebra finches. Science, 300, 125-127.

Braeckman, B.P., Houthoofd, K. \& Vanfleteren, J.R. (2001). Insulin-like signaling, metabolism, stress resistance and aging in Caenorbabditis elegans. Mech. Ageing Dev., 122, 673-693.

Clancy, D.J., Gems, D., Harshman, L.G., Oldham, S., Stocker, H., Hafen, E. et al. (2001). Extension of life-span by loss of CHICO, a Drosophila insulin receptor substrate protein. Science, 292, 104 106.

Deerenberg, C., Apanius, V., Daan, S. \& Bos, N. (1997). Reproductive effort decreases antibody responsiveness. Proc. $R$. Soc. Lond. B, 264, 1021-1029.

Faivre, B., Grégoire, A., Préault, M., Cézilly, F. \& Sorci, G. (2003). Immune activation rapidly mirrored in a carotenoid-based secondary sexual trait. Science, 300, 103.

Fang, Y.-Z., Yang, S. \& Wu, G. (2002). Free radicals, antioxidants, and nutrition. Nutrition, 18, 872-879.

Finkel, T. \& Holbrook, N.J. (2000). Oxidants, oxidative stress and the biology of ageing. Nature, 408, 239-247.

Gems, D. \& Partridge, L. (2001). Insulin/IGF signaling and ageing: seeing the bigger picture. Curr. Opin. Genet. Dev., 11, 287-292.

Gems, D., Sutton, A.J., Sundermeyer, M.L., Albert, P.S., King, K.V., Edgley, M.L. et al. (1998). Two pleiotropic classes of daf-2 mutation affect larval arrest, adult behavior, reproduction and longevity in Caenorhabditis elegans. Genetics, 150, 129-155.

Girodon, F., Blache, D., Monget, A.L., Lombart, M., BrunetLecompte, P., Arnaud, J. et al. (1997). Effect of a two-year supplementation with low doses of antioxidant vitamins and/or minerals in elderly subjects on levels of nutrients and antioxidant defense parameters. J. Am. Coll. Nutr., 16, 357-365.

Harman, D. (1957). Aging: a theory based on free radical and radiation chemistry. J. Gerontol., 2, 298-300. 
Holzenberger, M., Dupont, J., Ducos, B., Leneuve, P., Gélöen, A., Even, P.C. et al. (2003). IGF-1 receptor regulates lifespan and resistance to oxidative stress in mice. Nature, 421, 182 187.

Hsin, H. \& Kenyon, C. (1999). Signals from the reproductive system regulate the lifespan of C. elegans. Nature, 399, 362-366.

Kenyon, C., Chang, J., Gensch, E., Rudner, A. \& Tabtiang, R.A. (1993). A C. elegans mutant that lives twice as long as wild type. Nature, 366, 461-464.

Kirkwood, T.B.L. \& Austad, S.N. (2000). Why do we age? Nature, 408, 233-238.

Law, R. (1979). Optimal life histories under age-specific predation. Am. Nat., 113, 3-16.

Leroi, A.M. (2001). Molecular signals vs. the Loi de Balancement. Trends Ecol. Evol., 16, 24-29.

Lesgards, J.F., Durand, P., Lassarre, M., Stocker, P., Lesgards, G., Lanteaume, A. et al. (2002). Assessment of lifestyle effects on the overall antioxidant capacity of healthy subjects. Environ. Health Perspect., 110, 479-487.

Lithgow, G.J. \& Gill, M.S. (2003). Cost-free longevity in mice? Nature, 421, 125-126.

Loft, S., Astrup, A., Buemann, B. \& Poulsen, H.E. (1994). Oxidative DNA damage correlates with oxygen consumption in humans. FASEB J., 8, 534-537.

McKean, K.A. \& Nunney, L. (2001). Increased sexual activity reduces male immune function in Drosophila melanogaster. Proc. Natl. Acad. Sci. USA, 98, 7904-7909.

Martin, L.B., Scheuerlein, A. \& Wikelski, M. (2002). Immune activity elevates energy expenditure of house sparrows: a link between direct and indirect costs? Proc. R. Soc. Lond. B, 270, 153-158.

Niewiaroski, P.H. (2001). Energy budgets, growth rates, and thermal constraints: toward an integrative approach to the study of life-history variation. Am. Nat., 157, 421-433.

Nilsson, J.-A. (2002). Metabolic consequences of hard work. Proc. R. Soc. Lond. B., 269, 1735-1739.

Nordling, D., Andersson, M., Zohari, S. \& Gustafsson, L. (1998). Reproductive effort reduces specific immune response and parasite resitance. Proc. R. Soc. Lond. B, 265, 1291-1298.

Pieri, C., Moroni, F. \& Marra, M. (1996). Food restriction increases the protection of erythorcytes against the hemolysis induced by peroxyl radicals. Mech. Ageing Dev., 87, 15-23.

Råberg, L., Grahn, M., Hasselquist, D. \& Svensson, E. (1998). On the adaptative significance of stress-induced immunossupression. Proc. R. Soc. Lond. B, 265, 1637-1641.

Reznick, D.N. (1992). Measuring the costs of reproduction. Trends Ecol. Evol., 7, 42-45.

Reznick, D.N., Nunney, L. \& Tessier, A. (2000). Big houses, big cars, superfleas and the cost of the reproduction. Trends Ecol. Evol., 15, 421-425.

Rogowitz, G.L. (1996). Trade-offs in energy allocation during lactation. Am. Zool., 36, 197-204.
Rojas Wahl, R.U., Zeng, L., Madison, S.A., De Pinto, R.L. \& Shay, B.J. (1998). Mechanistic studies on the decomposition of water soluble azo-radical-initiators. J. Chem. Soc., Perkin Trans. 2, 9, 2009-2018.

Rose, M.R. \& Bradley, T.J. (1998). Evolutionary physiology of the cost of reproduction. Oikos, 83, 443-451.

Royle, N.J., Surai, P.F. \& Hartley, I.R. (2003). The effect of variation in dietary intake on maternal deposition of antioxidants in zebra finch eggs. Funct. Ecol., 17, 472-481.

Salmon, A.D., Marx, D.B. \& Harshman, L.G. (2001). A cost of reproduction in Drosophila melanogaster: stress susceptibility. Evolution, 55, 1600-1608.

SAS Institute (2001). SAS/STAT Software: Changes and Enhancements, version 8.2. SAS Publishing, Cary, NC.

von Schantz, T.V., Bensch, S., Grahn, M., Hasselquist, D. \& Wittzell, H. (1999). Good genes oxidative stress and conditiondependent sexual signals. Proc. R. Soc. Lond. B, 266, 1-12.

Stearns, S.C. (1992). The Evolution of Life Histories. Oxford University Press, Oxford.

Stocker, P., Lesgards, J.-F., Vidal, N., Chalier, F. \& Prost, M. (2003). ESR study of a biological assay on whole blood: antioxidant efficiency of various vitamins. Biochim. Biophys. Acta, 1621, 1-8.

Surai, P. (2002). Natural Antioxidant in Avian Nutrition and Reproduction. Nottingham University Press, Nottingham.

Svensson, E., Råberg, L., Koch, C. \& Hasselquist, D. (1998). Energetic stress, immunosuppression and the costs of an antibody response. Funct. Ecol., 12, 912-919.

Sze, J.Y., Victor, M., Loer, C., Shi, Y., Ruvkun, G. (2000). Food and metabolic signalling defects in a Caenorbabditis elegans serotonin-synthesis mutant. Nature, 403, 560-564.

Tsai, K., Hsu, T.-G., Cheng, H., Liu, T.-Y., Hsu, C.-F. \& Kong, C.-W. (2001). Oxidative DNA damage in human peripheral leukocytes induced by massive aerobic exercise. Free Radic. Biol. Med., 31, 1465-1472.

Velando, A. \& Alonso-Alvarez, C. (2003). Differential body condition regulation by males and females in response to experimental manipulations of brood size and parental effort in the blue-footed boody. J. Anim. Ecol., 72, 846-856.

Wang, Y., Salmon, A.B. \& Harshman, L.G. (2001). A cost of reproduction: oxidative stress susceptivility is associated with increased egg production in Drosophila melanogaster. Exp. Geront., 36, 1349-1359

Zera, A.J. \& Harshman, L.G. (2001). The physiology of life history trade-offs in animals. Annu. Rev. Ecol. Syst., 32, 95-126.

Editor, Volker Loeschcke

Manuscript received 11 December 2003

First decision made 15 January 2004

Manuscript accepted 5 March 2004

Originally submitted as a Report 